ojs.uv.es/index.php/qdfed

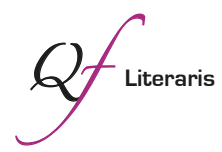

\title{
Pintores y ornatos para los Tejidos de seda en la Ilustración y la Academia Valenciana de Bellas Artes
}

\author{
Painters and ornaments for the silk fabrics in the Enlightenment \\ and the Valencian Academy of Fine Arts
}

María José López Terrada ${ }^{\mathrm{a}}$ Ester Alba Pagán ${ }^{\mathrm{b}}$

a Universitat de València. M.Jose.Lopez@uv.es
b Universitat de València. Esther.Alba@uv.es
Recibido: 11/04/2018. Aceptado: 21/06/2018

Resumen: Durante el siglo XVIII, Valencia se convirtió en el principal centro manufacturero español de tejidos de seda. Con el fin de proporcionar modelos originales para los mismos se creó en el seno de la Academia de Bellas Artes de San Carlos la "Escuela de Flores, Ornatos y otros diseños adecuados para Tejidos" en 1784. El presente artículo atiende a sus precedentes, sus principales protagonistas y analiza su funcionamiento, además de considerar la relación que mantuvo a lo largo de su trayectoria con la industria de la seda.

Palabras clave: seda; pintura de flores; Academia de Bellas Artes; Valencia; diseño textil.

Abstract: During the 18th century, Valencia turned in the main Spanish silk textile manufacturing center. In order to provide with original models for them, the "School of Flowers, Ornaments and other designs suitable for Tissues" was created within the Academy of Fine Arts of San Carlos in 1784. This article is about the precedents, the main protagonists and analyzes its ways of functioning, in addition to considering the relationship that she maintained throughout her history with the silk industry.

Keywords: Silk, Painting of flowers; Academy of Fine Arts; Valencia; Tissues design.

》) López Terrada, María José \& Alba Pagán, Ester. 2018. "Pintores y ornatos para los Tejidos de seda en la Ilustración y la Academia valenciana de Bellas Artes". Quaderns de Filologia: Estudis Literaris XXIII: 117-141. doi: 10.7203/ qdfed.23.13466 

Durante el último tercio del siglo XVIII, Valencia se convirtió en un importante centro de formación de diseñadores textiles y pintores de flores cuyo origen está directamente relacionado con la proyección económica que, desde comienzos de la centuria, había experimentado la industria valenciana de la seda ${ }^{1}$. La llegada de los Borbones a España había supuesto un cambio en los gustos de la Corte y la imposición progresiva de la moda francesa e italiana, dando lugar a un periodo que en el arte español se ha conocido como "extranjerizante" hecho, unido a la precaria situación en que se encontraba la industria textil española desde los años finales del siglo XVII, motivó que, para cubrir las necesidades de este nuevo ambiente cortesano se recurrieran a las importaciones de tejidos extranjeros procedentes, principalmente, de Lyon. Sin embargo, los nuevos monarcas mostraron muy tempranamente su interés por fomentar los talleres nacionales, creando nuevas manufacturas y modernizando y protegiendo las ya existentes (Benito, 2002, 2004).

La abundante producción de materia prima, la mayor resistencia a la crisis frente a los tradicionales centros sederos castellanos y andaluces y las medidas proteccionistas adoptadas por la monarquía son algunos de los factores que explican la conversión de Valencia en el núcleo manufacturero más importante de la sedería española durante el siglo XVIII.

Como ha indicado Ricardo Franch (2000), aunque la historia occidental de la seda se remonta al medievo, hemos de considerar el XVIII como el verdadero siglo de oro de la sedería europea, siendo Lyon el centro más importante en la producción textil y en la difusión de diseños innovadores y creativos (Franch, 2012). A partir de ese momento, el modelo lyonnais experimentará una amplia difusión debido a la

\footnotetext{
* The research leading to these results is in the frame of the "Silknow. Silk heritage in the Knowledge Society: from punched cards to big data, Deep learning and visual/ tangible simulations". Project, wich has received funding from the European Union's Horizon 2020 research and innovation programme under grant agreement No 769504. ${ }^{1}$ Sobre esta Escuela, ver: Aldana (1970); López Terrada (2001) y Sánchez (2008), donde se recogen las aportaciones anteriores. Para el desarrollo de la industria sedera: Rodríguez (1959); Franch (1996, 2000 y 2012) y Franch y Alba (2017).

${ }^{2}$ Molina (2012: 86): "la carencia de artistas españoles se vino a agravar por la falta de apoyos de la nueva dinastía, que dejó en manos de artistas franceses e italianos las grandes empresas artísticas de los Borbones, provocando en consecuencia un arte de influjo extranjerizante". Sobre esta cuestión existe un amplio debate historiográfico que puede seguirse en: Buendía (1998) y Morán (2003), principalmente.
} 
implantación de la moda francesa, y será especialmente efectivo en aquellos territorios dominados por la dinastía de los Borbones, como en el caso de España y Nápoles y Sicilia (Benito, 2001). Bajo las luces de la Ilustración e incentivadas desde la Corte, surgieron, en los territorios hispanos, las Reales fábricas bajo el auspicio de la monarquía, cuyo interés principal fue potenciar la industria bajo el desarrollo de las llamadas "artes útiles", que Anton Rafael Mengs introdujo en las cortes europeas, especialmente en la española (García Melero, 1998). El papel ejercido por la Real Fábrica de la seda, ubicada en Valencia (Jordán, Sancho y Benito, 2017: 19), es quizá uno de los menos conocidos. Esta iniciativa surgió a imitación de los sistemas de producción que en Lyon se habían desarrollado gracias a la implantación de un estudio de dibujo de flores y diseño, con el fin de impulsar la renovación de los modelos de tejido (Benito, 2003). La Real Academia de Bellas Artes de San Carlos de Valencia dispuso para tal fin el Estudio de Flores y Ornatos, bajo expreso deseo del rey Carlos III. Como se detallará más adelante, en él, los alumnos se introducían en el aprendizaje del dibujo o diseño, copiando motivos florales del natural, decoraciones all'antica en yeso, así como composiciones elaboradas por sus maestros, fundamentalmente Benito Espinós (1748-1818), José Antonio Zapata (1763-1837) y José Romá (1784-1852), entre otros (López Terrada, 2001; Alba, 2004).

Efectivamente, la instalación en Valencia, en 1753, de la Real Fábrica de seda, oro y plata de los Cinco Gremios Mayores de Madrid, tuvo como objetivo fundamental producir tejidos de alta calidad capaces de competir con los franceses (Capella; Matilla Tascón, 1957). Para ello, fue necesario introducir nuevos criterios empresariales, modernizar las técnicas y actualizar los diseños. Por esta razón se instalaron en Valencia por iniciativa de la Casa Real, los dibujantes lioneses René Marie Lamy, Jean Joseph Georget y Pierre Sauvan, así como el maestro fabricante de estofas de seda, oro y plata Jean Baptiste Felipot, con la intención de que formaran a los tejedores y diseñadores valencianos. Sin embargo, su actividad se vio pronto dificultada por la oposición de los sectores más tradicionales de la sedería local (Pérez Bueno, 1946: 326-339).

La necesidad de formar diseñadores textiles capaces de crear modelos originales para los tejidos y fomentar la independencia de Valencia respecto de las sederías lionesas determinó la creación de la Sala de "Flores, Ornatos y otros diseños adecuados para tejidos" en la Real 
Academia de Bellas Artes de San Carlos el 24 de octubre de 1778 (Aldana, 1970; López Terrada, 2001).

En la Real Orden por la que se creó este estudio se explican las condiciones especiales que reunía la ciudad de Valencia, la utilidad de esta enseñanza y los alumnos más adecuados para acudir a la misma:

Como los texidos de Seda de las manufacturas de Valencia forman uno de los principales objetos de la industria de aquellos naturales prometiendo considerables utilidades al Estado, siempre que consiga suministrar a los fabricantes dibuxos de flores, y de diferentes ideas Caprichosas para variar las estofas y exercitar su consumo; ha considerado el Rey que la Academia de $\mathrm{S}^{\mathrm{n}}$ Carlos se halla en este respecto, en caso distinto de otra Academia de las Tres Bellas Artes, pues allí deben concurrir directamente a dar fomento a aquellas manufacturas. Por tan justo motivo ha resuelto S. M. se establezca en dicha Academia una Sala separada para el estudio de flores, ornatos, y otros diseños adecuados para los texidos, creándose y dotándose la plaza de un maestro inteligente en esta parte y en la mecánica de adaptar los dibujos a las operaciones de los telares, el qual no haya de tener otra ocupación que la de enseñar y dirigir a los jóvenes. La Academia cuidará de destinar a este nuevo estudio a aquellos de entre sus discípulos que, manifestando quizá menos talento para hacer grandes progresos en alguna de las tres Nobles Artes, descubra, acaso, aquel genio y varia inventiva que se requiere para semejante empresa de diseños; bien que no se admitirá en dicha Sala a Discípulo alguno que no sepa ya diseñar las partes del cuerpo humano, en cuyo exercicio pueden solo adquirirse la exactitud y corrección necesarias; sin que el número de estos Dibujantes pueda exceder por ahora de doce. Y a fin de que abunden en ideas y se formen el gusto, procurará la Academia de San Carlos adquirir las colecciones de estampas de grotescos y ornatos antiguos que nos han quedado de los mejores Profesores de las Artes, donde la diversidad compite con lo exquisito y agradable de la invención ${ }^{3}$.

\footnotetext{
${ }^{3} 1778$, octubre 24 . Valencia. Real Orden por la cual el Rey aumenta la dotación de la Real Academia de San Carlos de Valencia y se crea el Estudio de Flores y Ornatos. Archivo de la Real Academia de Bellas Artes de San Carlos. Colección de las Reales Órdenes comunicadas a la Real Academia de San Carlos desde 1770 a 1828. Aldana, 1970, doc. 1: 262-263. El manuscrito de este documento se encuentra en el Archivo de la Real Academia de Bellas Artes de San Fernando, Relación con la Academia de San Carlos, 1761-1817, 35-2/2.
} 
Los académicos de San Carlos, sin embargo, dilataron tanto como pudieron la creación de los estudios de flores, pues no llegaron a entender el alcance del planteamiento Ilustrado con el que Carlos III creó estos estudios, que podría haber convertido los talleres tradicionales en una industria moderna con profesionales especializados. Consideraron esta actividad "artesanal", de escasa categoría para ser desempeñada por profesores académicos (López Terrada, 2001: 127).

El establecimiento definitivo de la "Escuela de Flores y Ornatos aplicados a los tejidos" en la Academia se produjo en 1784 por medio de la Real Orden de Carlos III, en la que nuevamente insistía en la importancia de los tejidos de seda valencianos y en la necesidad de formar diseñadores especializados capaces de crear modelos originales que acabaran con la dependencia de las sederías extranjeras ${ }^{4}$. En ella, el monarca equiparó oficialmente estos estudios en rango, dotación y dignidad con las restantes enseñanzas académicas.

Fue entonces cuando se nombró director de la Escuela a Benito Espinós (1748-1818), pintor especializado en el género, que sería el responsable de los estudios de flores desde 1778 hasta su jubilación en 1815.

Su personalidad artística y el concepto de enseñanza que con él se implantó en la Academia fueron decisivos para la formación del futuro núcleo de diseñadores y pintores valencianos de flores. Marcó además la dirección de esta enseñanza en otros centros artísticos de la época, como la Escuela de Dibujo de la Lonja de Barcelona, donde también existían pintores especializados en pintura de flores y adornos, gracias, entre otras cosas, a la labor llevada a cabo por el pintor Salvador Molet $(1773-1836)^{5}$.

Benito Espinós es, sin duda, el maestro de la Escuela valenciana de flores más conocido e influyente ${ }^{6}$. Comenzó su formación en el taller

\footnotetext{
${ }^{4}$ 1784, enero, 30. Valencia. Real Orden por la cual se establece en la Real Academia de San Carlos una Escuela para el estudio del dibujo de Flores y Ornatos. Archivo de la Real Academia de Bellas Artes de San Carlos, Colección Reales Órdenes (1770-1828). Se reproduce en el estudio de Aldana (1970), doc. 4: 267-271, aunque había sido dada a conocer previamente por Cavestany (1936-1940), doc. IV: 140-141 y Garín (1945), doc. 4: 86-89.

${ }^{5}$ Sánchez (2008: 323, 363-366).

${ }^{6}$ Sobre este artista, pueden verso los trabajos de Aldana (1970: 171-177); López Terrada (2001: 208-212); Alba Pagán (2004: 940-954) y, sobre todo, la revisión y últimas aportaciones de Sánchez (2008: 324-337; 490-524 y 634-648).
} 
de su padre, un reconocido pintor y grabador que participó en la fundación de la Academia de Santa Bárbara. José Espinós (1721-1784) fue, además, un importante coleccionista y bibliófilo que reunió una considerable cantidad de libros sobre pintura, grabado y dibujo, que le proporcionó un amplio conocimiento artístico ${ }^{7}$. Benito Espinós también aprendió de su padre la técnica de la pintura sobre vidrio que cultivó con especial habilidad.

Tras estos años de formación inicial, pasó a la Real Fábrica de seda, oro y plata de los Cinco Gremios Mayores de Madrid. Es muy probable que, antes de trabajar en ella como dibujante de diseños para tejidos de seda, recibiera las enseñanzas de los franceses Lamy, Georget y Sauvan, quienes, por aquel entonces, eran maestros de dibujo en esta institución.

Espinós mantuvo una estrecha relación con la Corte y, especialmente, con su círculo de ilustrados. En 1783, el Conde de Floridablanca le encargó un dibujo para una suntuosa colcha que Carlos III quería entregar como obsequio a la Reina de Portugal, lo que indica que, por estas fechas, sus trabajos como diseñador ya eran conocidos en la Corte. En 1997, con motivo de la exposición dedicada al arte de la seda en el siglo XVIII, Adela Espinós (1997: 199-201) localizó, entre los fondos del Museo de Bellas Artes de Valencia, dos dibujos que corresponden a este encargo.

En el modelo que se reproduce puede apreciarse el escudo de la reina de Portugal, realizado en papel aparte y posteriormente pegado. Se trata de un dibujo en lápiz negro y tiza sobre papel verjurado gris verdoso de 503 x $498 \mathrm{~mm}$, aunque su contorno es muy irregular. Esta obra fue tejida en la Fábrica de los Cinco Gremios de Madrid.

Con los dibujos realizados para esta obra, otros efectuados para una casulla adornada con los atributos de la Virgen y un Florero, Espinós consiguió el primer premio de Flores en el Concurso General de 1783, en la Real Academia de Bellas Artes de San Carlos de Valencia. Estos trabajos le facilitaron sin duda el nombramiento como director de la Escuela de Flores y Ornatos, un año más tarde.

A partir de este momento se inició la época de mayor prestigio de la Escuela de flores. Bajo la dirección de Benito Espinós, se mantuvo una

\footnotetext{
${ }^{7}$ Sobre José Espinós, discípulo de Luis Martínez y Evaristo Muñoz, y de cuya erudición se sirvió Orellana para realizar su biografía de artistas, pueden verse los trabajos de Benito Doménech (1980: 258-259) y Correa (1993: 131).
} 


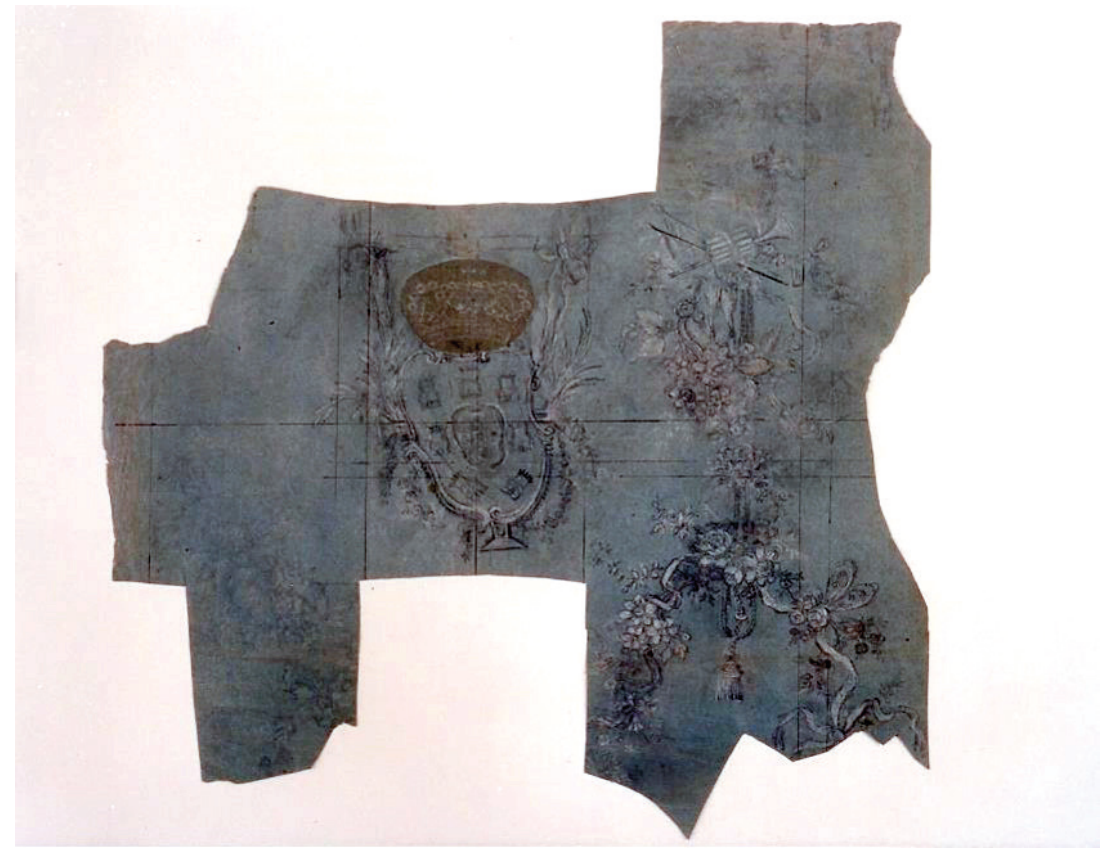

Fig. 1. Benito Espinós (1748-1818), Modelo para tejido, 1783,

(C) Museo de Bellas Artes de Valencia.

estrecha relación artística con los estudios florales de las Academias de Bellas Artes de Madrid, Murcia, Valladolid, Zaragoza, Barcelona y Tarragona (Aldana, 1970; Sánchez, 2008, 323).

José Antonio Zapata (1763-1837) ${ }^{8}$, artista plenamente formado en el seno de la Academia, sucedió a Benito Espinós en la Dirección de la Escuela de Flores, cargo que ocupó desde 1815 a 1837. Durante su época como director se hizo evidente la escasa utilidad que los estudios de flores tenían para la industria sedera. En 1830, el propio Zapata reconocía que "hallaba alguna resistencia en los discípulos para aplicar los dibujos a los tejidos" (Aldana, 1970:128), mientras existía una marcada inclinación hacia la pintura de flores, que en esta época era demandada por la burguesía local (Pérez Sánchez, 1997: 35).

\footnotetext{
${ }^{8}$ Sobre este pintor remitimos a los trabajos de Aldana (1970: 210-213); Pérez Sánchez (1996: 91; 1997: 43); López Terrada (2001: 267-269); Alba (2004: 2154-2175) y Pou (2013).
} 
Esta tendencia se acentuó durante los años en los que el pintor José Romá (1784-1852), discípulo de Espinós y Zapata, ocupó la Dirección, desde 1837 hasta $1852^{9}$. Durante este periodo triunfó una nueva tendencia decorativa floral totalmente desligada del concepto artesano que, al menos teóricamente, había regido durante el siglo XVIII.

José Romá fue sustituido por el pintor Vicente Castelló y Amat (1787-1860) en $1853^{10}$. Dos años más tarde, los estudios de Flores y Ornatos desaparecieron, siendo englobados en los estudios generales de pintura. En concreto, la materia fue sustituida por los estudios de dibujo lineal y adornos ${ }^{11}$. A partir de esta fecha ha de darse por concluida la actividad de la Escuela valenciana de flores.

Veamos ahora cuál era la misión y la organización de la misma, que quedaron claramente delimitadas en la Real Orden de 1784. Durante los meses de primavera, desde el 1 de abril al 31 de julio, los estudiantes debían dedicar dos horas diarias por la mañana al estudio de las flores del natural, realizando dibujos a lápiz "y otros de colorido al pastel, o aguadas, o al óleo", como señala la Real Orden ${ }^{12}$.

Es interesante destacar que las flores que los alumnos tomaban como modelo eran aquellas "que produce el tiempo en estos cuatro meses" y quedaba a cargo de la Academia "costear y tener prontas las flores que pidiese el mismo Director en dichos cuatro meses". En 1788, este turno de trabajo se alteró, estableciéndose el inicio de las clases en marzo y finalizándolas en julio "por haber enseñado la experiencia que las flores que presenta la estación, por su mucha variedad, son más a propósito al expresado fin que las que hay en el dicho julio y en particular las de los frutales, que después no las hay y ser éstas muy al caso para el fin a que se estableció dicho Estudio".

En la temporada de invierno, que se iniciaba en septiembre y terminaba en marzo, las clases, también de dos horas, se impartían por la

\footnotetext{
${ }^{9}$ Al respecto son fundamentales: Aldana (1970: 197-298); López Terrada (2001: 248249); Alba (2004: 2031-2058).

${ }^{10}$ La personalidad artística de Castelló y Amat ha sido investigada en: Aldana (1970: 162-163); Pérez Sánchez (1997: 45-46); López Terrada (2001: 199-201); Alba (2004: 694-857; (2008: 105-140; 2015: 115-145).

${ }^{11}$ Esta cuestión se amplía en Casado (1997: 42-43).

12 1784, enero, 30. Valencia. Real Orden por la cual se establece en la Real Academia de San Carlos una Escuela para el estudio del dibujo de Flores y Ornatos. Archivo de la Real Academia de Bellas Artes de San Carlos, Colección Reales Órdenes (1770-1828).
} 
noche y en ellas los alumnos debían "copiar los originales dibujados y coloridos", siendo obligación del Director "ordenar y hacer por sí un estudio de flores, sacadas del natural, y ayudadas de los realces del buen gusto y de los adornos; para los cuales la Academia le facilitará las lochas (sic) de Rafael, y otros ejemplares de los preciosos restos de la Antigüedad que deberán servirle exclusivamente de norma, a fin de ir formando el gusto de los discípulos".

Existen numerosos dibujos de los modelos realizados por Benito Espinós tomados del natural, que fueron copiados por multitud de alumnos y siguieron utilizándose incluso después de su muerte. De hecho, el Museo de Bellas Artes de Valencia tuvo que restaurar algunos de ellos que estaban muy estropeados por el continuo uso que de ellos hacían los alumnos de la Sala de Flores (López Terrada, 2001: 144-148).

Además de los dibujos, también se utilizaron estudios de flores al óleo de Benito Espinós para que sirvieran de modelo a sus alumnos durante la temporada de invierno. Entre los fondos de la Academia de Bellas Artes de Sant Jordi se encuentran tres obras de este artista que fueron enviadas en 1789 y que estaban destinadas a la enseñanza de esta especialidad en la Escuela de la Lonja (Fontbona y Durá, 1999: 38-39). Según opinan Jordan y Cherry (1995: 167), la exactitud botánica era el objetivo principal de estos ejercicios, que debían realizarse además en muy poco tiempo. La fluidez y ligereza de la pincelada en un estudio correctamente ejecutado se consideraban análogas a la "frescura" y "naturalidad" de las flores representadas.

Como se ha señalado, la Real Orden también estableció que la Academia proporcionaría al director las Logias de Rafael "y otros ejemplares de los preciosos restos de la Antigüedad que deberán servirle exclusivamente de norma, a fin de ir formando el gusto de los discípulos". Entre estas últimas obras se encontraban el tomo primero de $L a$ Pitture antiche d'Ercolano e contorni: incise con qualche spriegazione (Nápoli, 1757) de Ottavio Antonio Baiardi, que el propio Carlos III regaló a la Academia y que posteriormente serían completados con otros volúmenes. La institución, por su parte, adquirió en 1791 varias obras que servirían para el diseño ornamental, en especial para los jarrones de las composiciones florales, como la Suite de vases, dessinés par Petitot et gravés par Rossi (1764) y Raccolta de vasi diversi formati da illustri artefici e di varie targhe soprapposte alle fabriche, grabadas por 


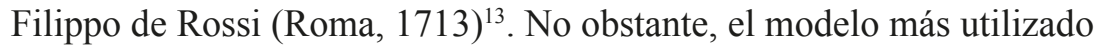
fue el primero. Como es sabido, la decoración de las paredes y el techo de las Logias del Vaticano realizadas por Rafael se considera el inicio del género de los "grutescos". Este término define un tipo de decoración mural, pintada, esculpida o modelada en estuco que, a principios del siglo XVI se extendió desde Italia a la mayoría de los países europeos, dejando una huella permanente en la decoración de interiores. Se caracteriza por el uso de motivo vegetales, animales, figuras humanas y seres fantásticos complejamente entrelazados y combinados, que proceden de los adornos encontrados en algunos edificios romanos, como la Domus Aurea de Nerón, a la que se accedía a través de una gruta, de ahí su denominación (Fatás; Borrás, 1991: 124). Entre los muchos dibujos conservados de este tema, puede citarse el realizado por Benito Espinós, fechado en 1787, que está realizado a partir de un pequeño fragmento de la pilastra IV de las Logias de Rafael en el Vaticano (Espinós, 1997: 202).

La importancia que se le concedía al dibujo en las enseñanzas académicas también se puso de manifiesto en estas disposiciones, pues como se ha mencionado, se estableció que no se admitiera a ningún discípulo en la Sala de Flores "sin que primero lo haya hecho en dibujar los modelos de la figura humana, y aún si pudiese ser del mismo natural".

La Real Orden también reglamentó los premios que debían incentivar "la aplicación de los discípulos a este Estudio". Como el estudio de flores se equiparó a las restantes enseñanzas de la Academia, se acordó dar tres premios en los Concursos Generales iguales a los de Pintura, además de tres ayudas o becas al concluir la temporada de primavera y tres más al finalizar la de invierno, igual a las que daba la Academia en las Salas de Natural, Yeso y Principios. También se decidió conceder una pensión a los premiados, de un año de duración, utilizando para ello los fondos que Fernando VI había dispuesto destinar para las becas de alumnos de la industria de la seda en 1756 .

Parece interesante conocer el funcionamiento de estos premios, pues la única información de la que se dispone en muchos casos es la

\footnotetext{
${ }^{13}$ Sánchez (2008: 322-323). Para un conocimiento más amplio de los fondos de la Biblioteca de San Carlos, resulta imprescindible el capítulo de Aldana (2004: 33-51). Para la utilización de grabados botánicos, ver López Terrada (2001: 147-148).
} 
presencia de sus alumnos en una convocatoria o la adjudicación de una pensión.

Las medallas o cantidades en metálico entregadas en los premios particulares y los Concursos Generales eran los medios de juzgar la aplicación de los discípulos de la Sala de Flores. Sin embargo, estos últimos, de periodicidad trienal, tenían un carácter público. En sus convocatorias, que eran distribuidas en las diferentes instituciones artísticas del país, se daban a conocer las normas, los temas y plazos estipulados. Las obras que los opositores tenían que presentar eran de dos tipos. Los primeros asuntos, que se determinaban y hacían públicos seis meses antes, constituían los ejercicios "de pensado". Tras ser examinados por la Junta General correspondiente, se acordaban los temas para los ejercicios "de repente", que debían llevarse a cabo en la Academia. Se disponía para ello de dos horas y los dibujos se realizaban en papeles iguales, rubricados por el secretario y no se firmaban. Los tres premios que correspondían a cada Clase se adjudicaban a partir de los votos obtenidos y se entregaban en una Junta Pública convocada para ello (Espinós, 1997: 84). Estos últimos ejercicios se realizaban rápidamente del natural, por lo que se sitúan en el extremo opuesto al detallismo de las obras realizadas por los pensionados. Además, en ellos se evidenciaba realmente la destreza del discípulo y su dominio del dibujo pues, como se ha señalado, para realizarlos se disponía únicamente de dos horas.

Una selección de las obras realizadas por estos artistas nos permitirá dar las claves interpretativas para definir las particularidades de la producción gestada en el seno de la academia valenciana. El método de enseñanza impuesto en la Escuela de Flores, su relación con la industria de la seda y los distintos tipos de artistas que cultivaron este género pictórico determinaron el carácter de las obras que realizaron.

Esta producción puede separarse básicamente en dos grandes grupos: los dibujos de flores y diseños para tejidos de los distintos artistas que estudiaron en la Academia, por una parte, y las composiciones de flores concebidas como obras independientes. El grupo que nos interesa en este caso es el primero.

En el Gabinete de Dibujos y Estampas del Museo de Bellas Artes de Valencia se conservan más de cuatrocientos cincuenta dibujos realizados por los maestros y discípulos de la Sala de Flores, que proceden 
de los fondos de la Real Academia de Bellas Artes San Carlos de Valencia ${ }^{14}$.

La técnica más usual empleada en estas obras fue el lápiz negro, que permite una amplia gama de grises, con toques de tiza o clarión para conseguir los efectos de luz. En alguna ocasión, también utilizaron la sanguina, tanto para los estudios de flores como para los diseños textiles. Los dibujos realizados a la aguada son menos numerosos pues, aunque esta técnica ofrecía posibilidades más amplias, exigía una mayor habilidad. Por último, muy raramente, se empleó la tinta a pluma. Este procedimiento implicaba una destreza todavía mayor, pues apenas existía posibilidad de corrección en caso de error (López Terrada, 2001: 145-146).

Como es lógico, entre los dibujos más antiguos figuran los de Benito Espinós que, como primer director de la Sala de Flores, se encargó de proporcionar aquellos que servirían de modelo a sus alumnos. Más de la mitad de las obras de los discípulos de esta Sala que actualmente se conservan son copias de los modelos de Espinós y, en menor medida, de José Antonio Zapata y José Romá que, como se ha adelantado, fueron igualmente directores del Estudio.

Naturalmente, existen diferencias en la calidad de estos dibujos, pero sus tipos básicos se mantuvieron invariables. Ya se ha señalado que, durante la temporada de primavera, los estudiantes dedicaban dos horas diarias al estudio de las flores del natural y durante el invierno, copiaban los modelos del maestro y diversas estampas. Junto a estas obras también se conservan los dibujos realizados por los premiados, los pensionados y, en general, los diseños con los que los distintos alumnos del Estudio participaron en los concursos de la Academia. Estas actividades permiten distinguir varios tipos de dibujos.

Los primeros son los estudios de flores realizados del natural o copiados de los modelos del maestro. A este grupo pertenece, por ejemplo, esta rama de capuchina de Jerónimo Navases (1787-post 1823), una planta muy habitual en las composiciones de flores de los artistas valencianos.

\footnotetext{
${ }^{14}$ Estos dibujos no han sido todavía, por desgracia, objeto de una publicación. No obstante, puede encontrarse reproducida una buena muestra en López Terrada (1998).
} 


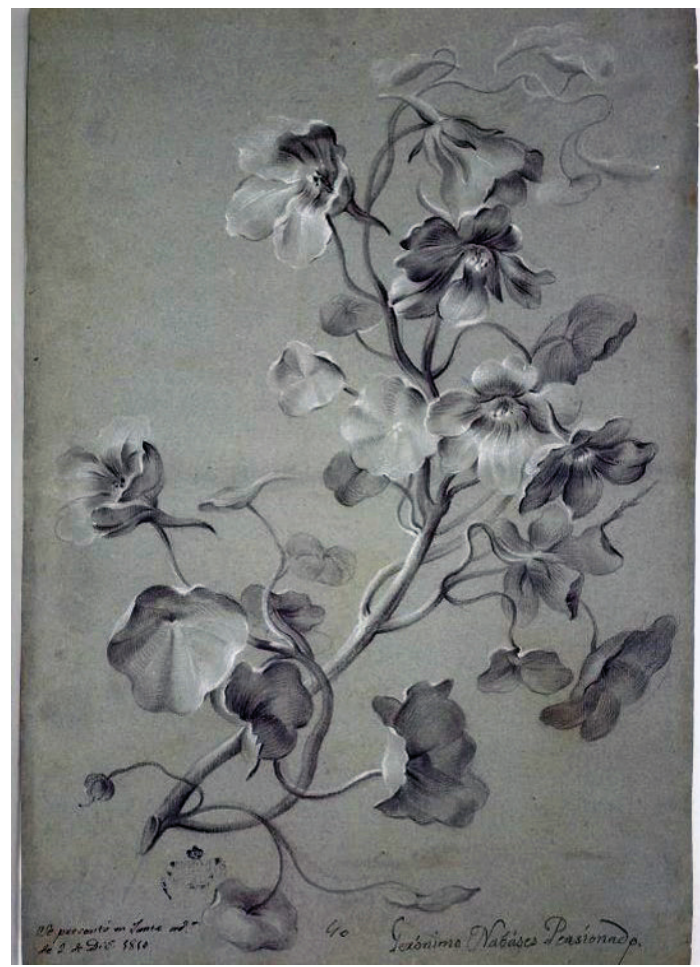

Fig. 2. Jerónimo Navases (1787-post 1823) Ramo de capuchinas, 1810, (C) Museo de Bellas Artes de Valencia.

Navases realizó este dibujo con lápiz negro y tiza sobre papel verjurado azul verdoso, de $490 \times 350 \mathrm{~mm}$, mientras disfrutaba de una pensión y, como se indica en el ángulo inferior izquierdo, lo presentó en la Junta Ordinaria de la Academia celebrada el 2 de diciembre de 1810. Parece interesante señalar que este autor, formado en la Academia de Bellas Artes de San Carlos, ha sido considerado un especialista en pintura de flores (Aldana, 1970: 187). Sin embargo, los datos que se conocen sobre su trayectoria profesional lo acercan más bien al tipo de pintor o dibujante de flores adaptadas a los tejidos que trabajaba para las fábricas de seda valencianas ${ }^{15}$.

${ }^{15}$ Resultan fundamentales en este sentido las aportaciones de López Terrada (2001: 238-239) y Alba (2004: 1555-1570). 
Dentro del grupo de dibujos que representan ramos y jarrones de flores realizados del natural o copiados de los modelos del maestro se encuentran los estudios en los que se agrupan dos o tres plantas ornamentales. Aunque es muy numeroso, este tipo puede ilustrarse con el soberbio ramo de Benito Senent (1746-post 1791), un dibujo en lápiz negro y tiza sobre papel verjurado gris de $400 \times 295 \mathrm{~mm}$, por el que se le concedió una gratificación el 3 de agosto de 1784 (López Terrada, 1998: vol. II, 530-531).

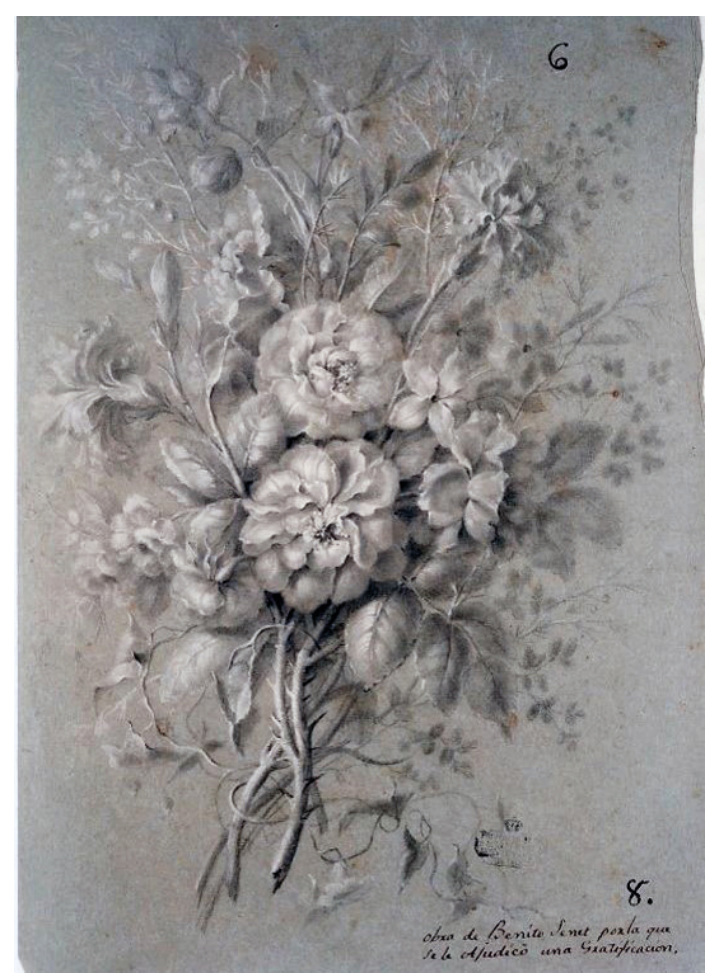

Fig. 3. Benito Senent (1746-post 1791). Ramo de rosas, claveles, jazmin y campanillas, (C) Museo de Bellas Artes de Valencia.

La historia de Benito Senent es realmente interesante. Al parecer, este pintor valenciano nacido en 1746 fue bachiller en Filosofía (Aldana, 1970: 230). Durante siete años se formó como dibujante y como pintor de muestras de tejidos con los maestros franceses de la Real Fábrica 
de los Cinco Gremios. Al acabar su aprendizaje, fue nombrado maestro interino de la escuela particular de adaptadores de flores a los tejidos que dirigía Pierre Sauvan en Valencia. Gracias a esta experiencia, el 1 de marzo de 1777 alcanzó el título de Maestro del Arte Mayor de la Seda. Un año antes de este nombramiento, había ingresado en la Sala de Principios de la Academia, donde permaneció cuatro años. Pasó luego a la Sala de Yeso y posteriormente a la del Natural, recibiendo en ellas varios premios. Durante estos años, combinó sus estudios con el trabajo para las fábricas de seda. Participó en el Concurso General de 1783, junto a Benito Espinós, Dionisio y Bernardo Medina, consiguiendo el segundo premio en la Clase de Flores. Un año más tarde, cuando se creó oficialmente la Escuela de Flores, se convirtió en uno de sus primeros discípulos. Este mismo año, el 3 de agosto de 1784, obtuvo el primer premio y la pensión correspondiente. Dos años después se le volvió a conceder el primer premio de la Sala de Flores. Parece que, a partir de este momento, dio por terminada su formación académica. Sin embargo, no acabó completamente su relación con la institución, pues el 28 de octubre de 1791 presentó varios dibujos para tejidos de seda con el fin de que fueran utilizados como modelos en la Clase de Flores. Actualmente el Museo de Bellas Artes de Valencia solo conserva otro dibujo fechado en 1786 que también representa un magnífico ramo de flores ${ }^{16}$.

Existe otro grupo de dibujos que está constituido por modelos decorativos que proceden de grabados. Los más numerosos son los que reproducen o se inspiran en colecciones de ornatos y grutescos antiguos acordes con la finalidad de esta enseñanza. Como se ha indicado, una de las obras que debía servir de modelo a los discípulos de la Sala de Flores eran las Logias de Rafael.

La obra que se reproduce corresponde a Pascual Soto (1772-post 1840) un pintor formado en la Academia de San Carlos que, al parecer, también trabajó como dibujante de muestras de flores para tejidos. La última noticia de su actividad en la institución corresponde al año 1837, cuando se presentó a la plaza de director de la Sala de Flores, tras la jubilación de Zapata, cargo que consiguió José Romá. Actualmente se desconoce su producción y la de sus tres hijos, Pascual, Manuel y Vicente, que también se dedicaron a la pintura de flores. La única obra

\footnotetext{
${ }^{16}$ López Terrada (2001: 257-258). La pintura de bodegones de este artista, que en este caso no se considera, la ha dado a conocer Sánchez (2008: 339-342).
} 
localizada hasta el momento, un Jarrón y cesta de flores, es un lienzo conservado en el Museo de Bellas Artes de Valencia por el que posiblemente fue nombrado Académico de Mérito en 1832. En este Museo, también se guardan diecinueve dibujos, la mayoría fechados en los años en que Pascual Soto fue pensionado de la Sala de Flores ${ }^{17}$. El dibujo que vemos, de 590 x $445 \mathrm{~mm}$, fue realizado en 1796 y reproduce un fragmento de las Logias de Rafael correspondiente a la parte exterior de la pilastra n. ${ }^{\circ}$ XIII (Espinós, 1997: 260).

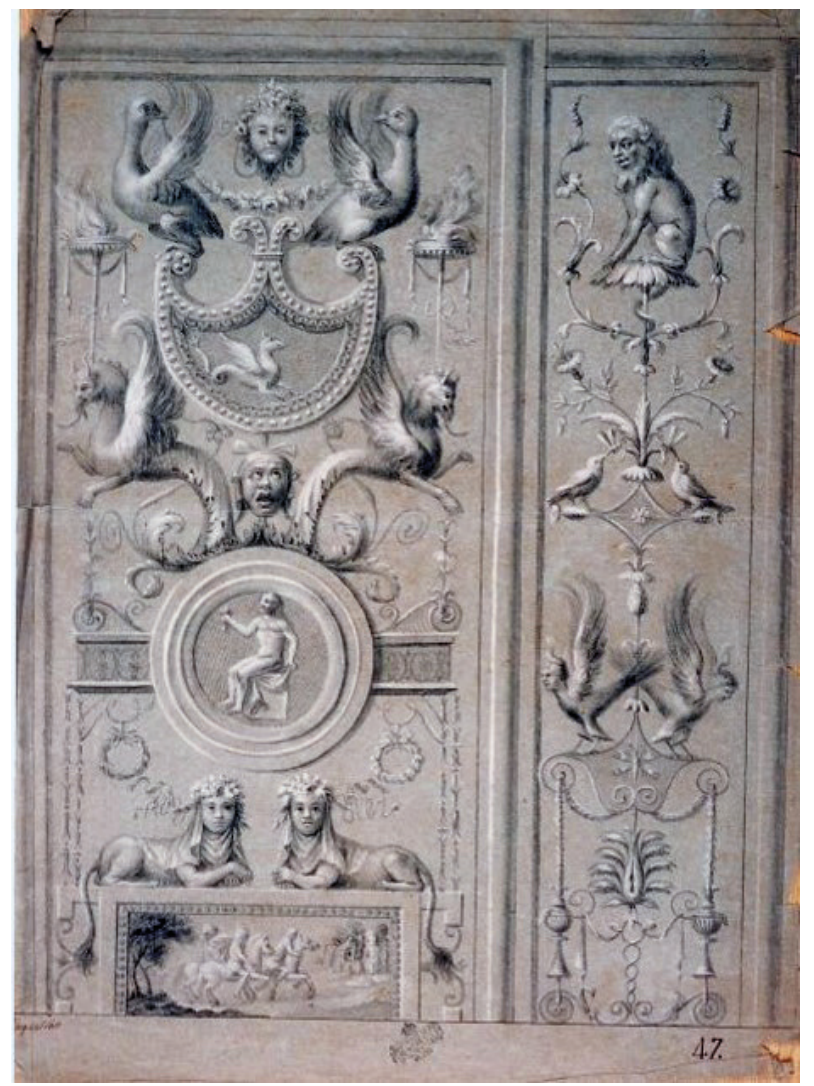

Fig. 4. Pascual Soto (1772-post 1840). Modelo para tejido: cenefas con plafones y elementos decorativos, (C) Museo de Bellas Artes de Valencia.

${ }^{17}$ Aldana (1970: 205-206); López Terrada (2001: 258-259); Alba (2004: 2085-2089). 
En otras ocasiones, las composiciones decorativas estaban tomadas de grabados franceses, como sucede, por ejemplo, en el modelo para tejido del pintor José Rosell (1778-post 1837), que acabaría consiguiendo el nombramiento de Académico de Mérito en Pintura de flores en 1806.

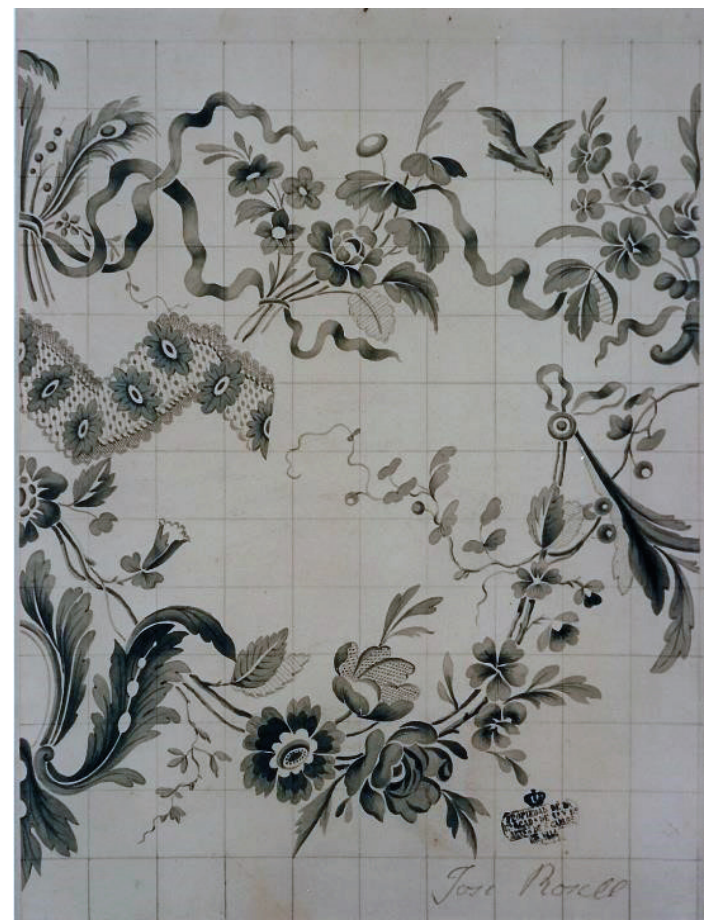

Fig. 5. José Rosell (1778-post 1837). Modelo para tejido: cenefas ornamentales de flores. Dibujo de aguada en tinta china sobre papel granuloso agarbanzado cuadriculado a lápiz. (c) Museo de Bellas Artes de Valencia.

Su historia también merece mencionarse brevemente pues, además de tener un estudio privado de pintura en su domicilio a principios del siglo XIX, también trabajó para la fábrica de tejidos de Antonio Miguel. En 1837, al jubilarse Zapata, se presentó a la plaza de director de la Sala de Flores junto a Pascual Soto y José Romá, siendo elegido este último. Actualmente, las únicas obras que se conservan de este artista en el Museo de Bellas Artes de Valencia son los nueve dibujos realizados 
durante su época de pensionado ${ }^{18}$. Según Espinós (1997: 257), el dibujo que se considera, elaborado con aguada de tinta china sobre papel granuloso cuadriculado a lápiz y de 350 × $288 \mathrm{~mm}$, fue realizado "a partir de uno de los grabados que el francés Henri Salembier (1753-1820) ejecutó en 1777 de un panel para una puerta, estilo Luis XVI, para la serie de seis láminas impresas por Lepère y Avaulez", que conocemos gracias a las reproducciones incluidas en la obra de Désiré Guilmard, titulada Les Maitres ornemantistes. Dessinateurs, Peintres, Architectes, Sculpteurs et Graveurs. Ecoles Francaise, Itallienne, Allemande et des Pays-Bas (Flamande \& Hollandaise), publicada en Paris en 1880.

Como puede comprobarse, dentro de los diseños aplicados a los tejidos con motivos florales existen algunas diferencias. En principio, este tipo de obras exigía una simplificación tanto de los modelos de flores como de los ornamentales realizados con anterioridad, de forma que permitiera su utilización en los talleres textiles. Esta simplificación fue en ocasiones tan severa que impide la identificación de las especies botánicas ornamentales representadas, como sucede, por ejemplo, en el modelo para tejido de José Rosell. Sin embargo, en otros casos, la simplificación parte claramente de un dibujo realizado del natural que, además de permitir su aplicación al tejido, representa un motivo floral claramente reconocible. Es lo que ocurre en algunas muestras de estampado realizadas sobre raqueta para facilitar su aplicación al tejido como la de 1813 de Sebastián Giner (1782-post 1816), que posiblemente trabajara también para la industria sedera ${ }^{19}$. En ella se incluye un ramo de anémonas, espuelas de caballero y una adormidera.

En el extremo contrario se encuentran los diseños que contienen ramilletes de flores sin modificar el realismo y el tipo de representación de los estudios del natural. En varios modelos para tejidos se puede comprobar la similitud de las flores realizadas previamente, apenas sin cambios. Así sucede, por ejemplo, en el caso de Bernardo Llácer que realizó un estudio del natural de un ramo de rosas y lo utilizó el mismo detallismo en la reproducción de las flores en un modelo para tejido de $1817^{20}$.

\footnotetext{
${ }^{18}$ Sobre este artista: Aldana (1970: 201-202); López Terrada (2001: 254-255); Alba (2004: 2060-2064).

${ }^{19}$ Esta noticia es ratificada en: Aldana (1970: 181-182); Espinós (1997: 225); López Terrada (2001: 221-222).

${ }^{20}$ Estos dibujos se reproducen en López Terrada (2001: 324 y 325). Según Aldana (1970: 207), este discípulo de la Sala de Flores también trabajó como pintor de flores
} 


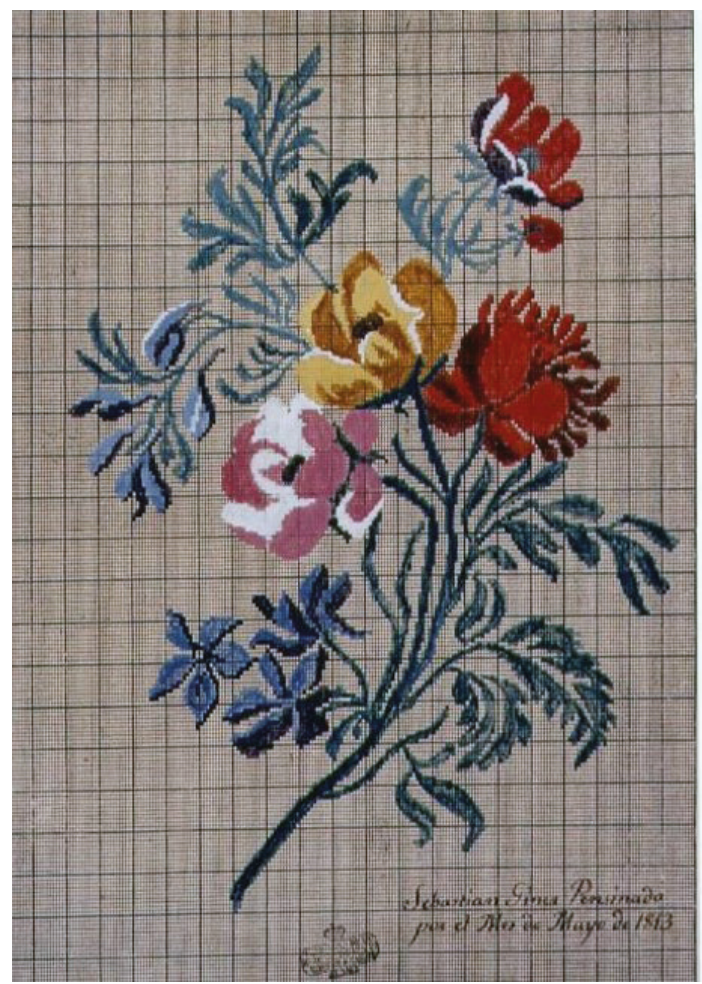

Fig. 6. Sebastián Giner (1782-post 1830). Muestra de estampado, 1813, (C) Museo de Bellas Artes de Valencia.

Existe otro tipo de diseños para tejidos en los que las plantas representadas parecen haber sido escogidas por sus connotaciones simbólicas. El ejemplo más claro lo constituye el dibujo del prácticamente desconocido Francisco Javier Nebot (ca. 1810-post 1837) que representa una medalla con la Inmaculada Concepción. En él, se acompaña de sus símbolos vegetales más habituales: el ciprés, la palmera, las rosas, el

para la industria de la seda. Sin embargo, este mismo autor Aldana (1970: 183) recogió como última noticia de Bernardo Llácer "su petición de poder pasar a las Salas de Matemáticas y Escultura para ampliar conocimientos". Es posible que esta noticia corresponda al escultor valenciano Bernardo Llácer y Viana que, al parecer, no está relacionado con el alumno de la Sala de Flores. 
olivo y las azucenas, estas últimas en manos de los ángeles ${ }^{21}$. Este mismo hecho ocurre en otros dibujos, como el realizado solo en su cuarta parte para una cortina de sagrario por Juan Bautista Brú (1773-post 1801), del que igualmente se tienen pocas noticias, en 1801. En él también se han incluido plantas simbólicas como la vid, pero las flores que configuran el ramo parecen tener una función más bien decorativa ${ }^{22}$.

Para terminar con este breve recorrido por los diseños de la Escuela de Flores puede destacarse el interesante grupo compuesto por alegorías.

Una de las más hermosas es la Alegoría de la Eucaristía de Vicente Catalá (1801-post. 1823), del que apenas quedan noticias de su paso por la Academia. En este modelo para tejido, fechado en torno a 1819, los elementos religiosos compiten en importancia con los motivos vegetales. Prueba de ello es que el eje central está ocupado no solo por la sagrada Forma, el cáliz y el cordero, sino también por un grandioso jarrón de flores ${ }^{23}$.

Menos conocidas son las complejas alegorías realizadas por José Romá, el tercer director de la Escuela de Flores. En el Museo de Bellas Artes de Valencia se conservan seis magníficos dibujos firmados por este artista que representan los primeros seis meses del año. Están protagonizadas, respectivamente, por Juno (para el mes de enero); Neptuno (para febrero); Marte (para marzo); Venus (para abril), Apolo (para mayo) y Mercurio (para junio). En la Alegoría del mes de febrero, Neptuno, coronado y con un tridente, acompañado por una ballena y apoyado sobre una gran concha, se alza sobre un alto pedestal decorado con animales marinos. La parte inferior se reserva para la representación del signo de piscis, con dos peces inscritos en un círculo coronado por un tridente, con tritones y caballos de mar a los lados. El fondo lo ocupa una vista parcial de un gigantesco barco que alude a la protección del

\footnotetext{
${ }^{21}$ Este modelo para tejido consiste en un dibujo realizado con lápiz negro y tiza con toques de sanguina en papel azul, de 556 x 419 mm. Se reproduce en Espinós (1997: 238). ${ }^{22}$ Se trata de un dibujo realizado con lápiz negro y tiza sobre papel verjurado azul de 435 x $339 \mathrm{~mm}$. Al pie se indica que se trata del ejercicio "de repente" del Concurso General de 1801 por el que consiguió el segundo premio. Espinós (1997: 193) y López Terrada (2001: 326), donde se reproduce.

${ }^{23}$ Se reproduce en Espinós (1997: 195); López Terrada (2002: 327) y Alba (2004: 869870 y 874$)$.
} 
dios del mar sobre los navegantes. Este tipo de obras refleja la importancia del lenguaje alegórico en el ámbito de la institución académica ${ }^{24}$.

Podemos concluir diciendo que, a pesar de los esfuerzos y de la intensa actividad formativa de estos innovadores estudios, los planes ilustrados que perseguía Carlos III al crear la Sala de Flores en la Academia de San Carlos no llegaron plenamente a realizarse, principalmente, porque los académicos nunca llegaron a aceptar la intención utilitaria de estos estudios. Sin embargo, tampoco puede mantenerse la idea de que los diseños de sus maestros y discípulos fueran totalmente inútiles para la industria de la seda. Además de su relación con la Corte, como se ha avanzado, en el momento de mayor prestigio de la Escuela de Flores valenciana, se mantuvo una estrecha relación con los centros docentes de Madrid, Valladolid, Zaragoza, Barcelona, Mallorca, Tarragona y Murcia. Asimismo, la influencia de estos diseños se extendió a otros campos al margen de la industria de la seda, como fue la cerámica valenciana de la época. En este sentido, numerosos artistas formados en la Sala contribuyeron a renovar los motivos de la azulejería seriada valenciana de las últimas décadas del siglo XVIII (Pérez Guillén, 1996: 181-182; Feliu Franch, 2001: 133-143).

En cualquier caso, lo que resulta indudable es que el método de enseñanza de la Escuela valenciana creó al grupo de pintores de flores mejor formados de España, cuya producción continuaría hasta bien entrado el siglo XIX. Este método, con un proceso de creación de los diseños y adornos florales iniciado con el estudio de flores del natural, pasando por el modelo de tejido y su puesta en carta, sería adaptado por las primeras fábricas de tejidos valencianas que comenzaban a modernizarse con la implantación de los telares Jacquard en los primeros años del siglo XIX. Es el caso de la fábrica de Garín (1820), cuya colección debe estudiarse en consonancia con los estudios académicos, las formas de hacer importadas desde Francia y las maneras tradicionales de la sedería valenciana, en un complejo entramado de relaciones con cuyo hilo está tejida la historia de la seda valenciana y que en la actualidad pervive, junto a otras pequeñas industrias de la seda, como muestra de un patrimonio vivo: elocuente transmisión de un pasado cultural que debe ser reconocido y justamente valorizado.

\footnotetext{
${ }^{24}$ Para un desarrollo más amplio de esta cuestión, ver López Terrada (2016).
} 


\section{Bibliografía}

Alba, Ester. 2002. El gusto decorativo en la corte de Carlos IV y Fernando VII: la pintura y los pintores valencianos en las "casitas" del Real Sitio de San Lorenzo de El Escorial. En Archivo de Arte valenciano 84: 89-96.

Alba, Ester. 2004. La pintura y los pintores valencianos durante la Guerra de la Independencia y el reinado de Fernando VII (1808-1833). Valencia: Universitat de València.

Alba, Ester. 2008. Vicente Castelló y su taller. Las pinturas murales en las iglesias de la Vall d'Albaida. En Terol, V. (coord.) II Congrés d'Estudis de la Vall d'Albaida. Valencia: Institució Alfons el Magnànim, 105-140.

Alba, Ester. 2015. Un encàrrec de la duquessa d'Almodòvar per a l'esglèsia de Xaló. En Ballester, I. Dos-cents anys a l'ombra de la duquessa d'Almodovar. Valencia: Edicions 96, 115-145.

Aldana, Salvador. 1970. Pintores valencianos de flores (1766-1866). Valencia: Instituto Alfonso el Magnánimo.

Aldana, Salvador. 1997. La "Escuela de Flores y Ornatos" y el Arte de la Seda en Valencia. En Arte de la seda en la Valencia del siglo XVIII. Valencia: Fundación Bancaja, 63-79.

Aldana, Salvador. 2004. L'Arxiu i la Biblioteca de l'Acadèmia de Santa Bàrbara i de la Reial Acadèmia de Sant Carles. En L'Acadèmia de Santa Bàrbara i la Reial de les Tres Nobles Arts de San Carles. Cent Anys de Ensenyament. Valencia: Universitat Politècnica de València, 33-51.

Benito, Pilar. 2001. Silk, baldachins and embroidered landscapes. En The Majesty of Spain: Royal collections from the Museo del Prado and the Patrimonio Nacional. Madrid, 160-162.

Benito, Pilar. 2002. Tejidos y bordados de seda para la Corona española en tiempos de Felipe V. En El arte en la corte de Felipe V. Madrid, 385396.

Benito, Pilar. 2003. La seda en Europa meridional desde el Renacimiento hasta la aparición del mecanismo Jacquard. En Textil e indumentaria: materias, técnicas y evolución. Madrid: Universidad Complutense de Madrid, 150-164.

Benito, Pilar. 2004. Reales fábricas de tejidos de seda. En Jornadas sobre las Reales Fábricas (2002). La Granja de San Ildefonso, 111-128.

Benito Doménech, Fernando. 1980. Pinturas y pintores del Real Colegio del Corpus Christi. Valencia: Federico Domenech.

Buendía, Rogelio. 1998. La pintura española del siglo XVIII. Aproximación al estado de la cuestión. En: I Congreso Internacional de Pintura Española del siglo XVIII. Marbella: Museo del Grabado Español Contemporáneo, 13-24. 
Capella, Miguel \& Matilla Tascón, Antonio. 1957. Los Cinco Gremios Mayores de Madrid. Madrid.

Casado, E. 1997. La huella de la Academia en la pintura valenciana del siglo XX. En Maestros de la pintura valenciana del siglo XIX en el Museo del Pardo. Madrid, Museo del Prado, 3-49.

Cavestany, Julio. 1936-1940. Floreros y Bodegones en la Pintura Española. Madrid: Sociedad Española de Amigos del Arte.

Correa, Antonio. 1983. Diccionario crítico de grabadores valencianos del siglo XVIII. En Fernando Selma. El Grabado al servicio de la cultura ilustrada. Barcelona: La Caixa, 125-152.

Espinós, Adela. 1997. Dibujos de flores aplicados al tejido en la Colección de la Real Academia de San Carlos. En Arte de la seda en la Valencia del siglo XVIII. Valencia: Fundación Bancaja, 81-105.

Fatás, Guillermo \& Borrás, Gonzalo M. 1991. Diccionario de términos de arte y elementos de arqueología, heráldica y numismática. Madrid: Alianza.

Feliu Franch, Joan. 2001. La arquitectura esmaltada. Cerámica arquitectónica de Onda en el siglo XIX. Onda (Castellón): Ajuntament d'Onda.

Fontbona, Francesc \& Durá, Victoria. 1999. Catàleg del Museu de la Reial academia Catalana de Belles Arts de Sant Jordi (I- Pintura). Barcelona: Reial Acadèmia Catalana de Belles Arts de Sant Jordi.

Franch, Ricardo. 1996. La sedería valenciana en el siglo XVIII. En España y Portugal en las rutas de la seda. Diez siglos de producción y comercio entre Oriente y Occidente. Barcelona: Universitat de Barcelona, 201221

Franch, Ricardo. 2000. La sedería valenciana y el reformismo borbónico. Valencia: Institució Alfons el Magnànim.

Franch, Ricardo. 2012. Del "vellut" al espolín. Estudios sobre la industria valenciana de la seda en la edad moderna. Valencia: Obrapropia.

Franch, Ricardo \& Alba, Ester. 2017. Los paisajes de la seda. En Paisajes turísticos valencianos, paisajes valiosos, paisajes valorados. Valencia: Universitat Politèctica de València, 862-880.

García Melero, José E. 1998. Arte español de la Ilustración y del siglo XIX. En torno a la imagen del pasado. Madrid: Ediciones Encuentro.

Garín Ortiz del Taranco, Felipe María. 1945. La Academia valenciana de San Carlos. El movimiento académico europeo y su proyección en Valencia. Valencia: Real Academia de Bellas Artes de San Carlos (ed. 1993).

Géal, Pierre. 1999. L'Invention de l'école espagnole aux XVIII ${ }^{\mathrm{e}}$ et XIX' siècles. Cahiers du GRIMH 1: 293-303.

Guilmard, Désiré. 1880. Les Maitres ornemantistes. Dessinateurs, Peintres, Architectes, Sculpteurs et Graveurs. Écoles Francaise, Itallienne, Allemande et des Pays-Bas (Flamande \& Hollandaise). Paris. 
Jordan, William B. \& Cherry, Peter. 1995. El bodegón español de Velázquez a Goya. Londres: National Gallery.

López Terrada, María José. 1998. Tradición y cambio en la pintura valenciana de flores en la transición de la Ilustración al Romanticismo. Tesis doctoral inédita de la Universitat de València.

López Terrada, María José. 2001. Tradición y cambio en la pintura valenciana de flores (1600-1850). Valencia: Ayuntamiento de Valencia.

López Terrada, María José. 2016. Entre el lenguaje alegórico y la pintura de flores: a propósito de una obra de Miguel Parra (180-1846). Goya 356: 238-251.

López Terrada, María José. 2017. Recuperando del olvido a artistas valencianos: el caso del pintor Antonio Vivó Noguera (1772-ca. 1834). Ars Longa 26: 141-156.

Molina, Álvaro. 2012. Visualizando el género en la Historia del Arte. El siglo XVIII español como caso de estudio. Anuario del Departamento de Historia y Teoría del Arte 24: 79-92.

Morán Turina, Miguel. 2003. La difícil aceptación de un pasado que no fue malo. En El arte en la corte de Felipe $V$, catálogo de la exposición (Patrimonio Nacional, 2003). Madrid, 23-40.

Pérez Bueno, Luis. 1946. Fábricas de Tejidos de seda, oro y plata de Valencia. Su relación con los cinco Gremios Mayores de Madrid. Años 1753, 1754 y 1755. En Archivo de Arte Valenciano 18: 326-339.

Pérez Guillén, Inocencio Vicente. 1996. Cerámica arquitectónica valenciana. Los azulejos de serie (s. XVI-XVII) (2 vol.). Valencia: Generalitat Valenciana, n. ${ }^{\circ} 26,141-156$.

Pérez Sánchez, Alfonso Emilio. 1983. Pintura española de Bodegones y Floreros. De 1600 a Goya. Madrid: Ministerio de Cultura.

Pérez Sánchez, Alfonso Emilio. 1997. La pintura valenciana de flores. En Arte de la seda en la Valencia del siglo XVIII. Valencia: Fundación Bancaja, 31-47.

Pou, Miguel. 2013. Una pintura desconeguda de José Zapata i Nadal dins de la Mallorca il·lustrada de 1803. En Archivo de Arte Valenciano 94: 105113.

Rodríguez, Santiago. 1959. El arte de las sedas valencianas en el siglo XVIII. Valencia: Institución Alfonso el Magnánimo.

Sánchez, Andrés. 2008. La pintura de bodegones y floreros en España en el siglo XVIII. Madrid: Fundación Arte Hispánico.

Sancho, José Luis; Jordán, J. \& Benito, Pilar. 2017. Carlos III. Majestad y Ornato. Madrid: Patrimonio Nacional. 
